\title{
In Situ Synthesis of (M:Nb,Ta)C/Ni35 Composite Coating Cladded on 40Cr Steel
}

\author{
Gaoqiang Jiang, Chengyun Cui *, Lu Chen, Yucheng Wu and Xigui Cui
}

check for updates

Citation: Jiang, G.; Cui, C.; Chen, L.; Wu, Y.; Cui, X. In Situ Synthesis of (M:Nb,Ta)C/Ni35 Composite Coating Cladded on 40Cr Steel. Materials 2021, 14, 7437. https://doi.org/10.3390/ ma14237437

Academic Editor: Maria Isabel Osendi

Received: 27 September 2021 Accepted: 13 November 2021 Published: 3 December 2021

Publisher's Note: MDPI stays neutral with regard to jurisdictional claims in published maps and institutional affiliations.

Copyright: (c) 2021 by the authors. Licensee MDPI, Basel, Switzerland. This article is an open access article distributed under the terms and conditions of the Creative Commons Attribution (CC BY) license (https:// creativecommons.org/licenses/by/ $4.0 /)$.
School of Mechanical Engineering, Jiangsu University, Zhenjiang 212013, China; 2221903027@stmail.ujs.edu.cn (G.J.); 2112003006@stmail.ujs.edu.cn (L.C.); 2112003004@stmail.ujs.edu.cn (Y.W.); 2211803033@stmail.ujs.edu.cn (X.C.)

* Correspondence: cuicy@ujs.edu.cn; Tel.: +86-511-88797198; Fax: +86-511-88780219

\begin{abstract}
To improve the wear and corrosion resistance of the pump barrel material (40Cr steel), a (M:Nb,Ta)C/Ni35 composite cladding coating by in situ synthesis of composite carbides was conducted. The effects of ceramic micro-particles content on the phase composition, microstructure of the coating, structural characteristics of $(\mathrm{M}: \mathrm{Nb}, \mathrm{Ta}) \mathrm{C}$ and the tribology and electrochemical corrosion behavior were systematically studied. The increase of ceramic micro-particles changed the morphology of $(\mathrm{M}: \mathrm{Nb}, \mathrm{Ta}) \mathrm{C}$ with the size from sub-micron to micron. The $(\mathrm{M}: \mathrm{Nb}, \mathrm{Ta}) \mathrm{C}$ dispersed along the grain boundary inhibits the growth of the grains. During friction, the spherical structure exhibited a rolling lubrication effect and the petal structure provided a stronger attachment ability to resist the shear. The corrosion occurred at the grains, exhibiting corrosion pits, in which the high content ceramic micro-particles were relatively shallow. Moreover, a few dot corrosion pits were distributed along the grain boundaries without $(\mathrm{M}: \mathrm{Nb}, \mathrm{Ta}) \mathrm{C}$. Therefore, to improve the corrosion resistance, a thin composite carbide coating with good wear and corrosion resistance was prepared.
\end{abstract}

Keywords: in situ synthesis; laser cladding; composite coating; (M:Nb,Ta)C; 40Cr

\section{Introduction}

The pump barrel material (40Cr steel) in the energy field works for a longer time under severe conditions, such as oil fields, seawater and sand. It is prone to surface failures such as wear and corrosion, which puts forward higher requirements for wear resistance and corrosion resistance. [1,2]. Laser cladding technology can significantly improve the mechanical properties of the parts surface to achieve protection [3,4]. However, the cladding thickness is generally higher than $1 \mathrm{~mm}$, and the dilution rate of the coating and the thermal effect on the thin-walled pump barrel material is high [5]. The parameters were adjusted, and a thin coating $(0.5 \mathrm{~mm})$ with a dilution rate of $5.71 \%$ was prepared. Another problem is that when conducting performance tests, it was found that the low protective coating limits its all-around performance compared with the traditional coating thickness.

In recent years, many scholars introduced ceramic micro-particles, such as carbides, nitrides and oxides [6,7]. Recently, in order to improve the surface property, composite carbide ceramic micro-particles have been exploited to strengthen the materials [8]. Nam et al. [9] utilized gas tungsten arc cladding to prepare ( $\mathrm{Ti}, \mathrm{W}) \mathrm{C}-\mathrm{Al}_{2} \mathrm{O}_{3}$ ceramic reinforced metal matrix composites (MMC). $(\mathrm{M}: \mathrm{Ti}, \mathrm{W}) \mathrm{C}$ particles were densely distributed in the $\mathrm{MMC}$, and the hardness was significantly better than that of the single carbide ceramic TiC. Wang et al. [10] studied the Fe-based alloy surface layer reinforced by TiC-VC particles. In this study, the generated TiC-VC particles $(2 \sim 4 \mu \mathrm{m})$ were uniformly dispersed in the matrix, thereby obtaining excellent hardness of the surfacing coating. Gu et al. [11] conducted immersion corrosion tests on $\mathrm{TiC}-20 \mathrm{vol} \% \mathrm{SiC}$ and $\mathrm{TiC}-40 \mathrm{vol} \% \mathrm{SiC}$ in molten FLiNaK salt at $800{ }^{\circ} \mathrm{C}$; . The corrosion result showed that $\mathrm{SiC}$ improved the corrosion resistance of $\mathrm{TiC}$, which in turn improved the corrosion resistance of the entire coating. Nevertheless, the research on $(\mathrm{M}: \mathrm{Nb}, \mathrm{Ta}) \mathrm{C}$ composite carbide has not been reported. The atomic sizes 
of $\mathrm{Nb}$ and Ta are very similar $(0.1429 \mathrm{~nm}$ and $0.1430 \mathrm{~nm}$, respectively), and the crystal structures are also the same (both are FCC structures). Small lattice distortion caused by similar atomic size can improve stability, and the same type of crystal structure enhances solubility. In addition, compared with the external method, the uniform reinforcement phase synthesized in situ is more compatible with the matrix with higher interface bonding strength and thermodynamic stability.

Therefore, the purpose of this work is to improve the wear resistance and corrosion resistance of the thin coating through the introduction of composite carbide ceramic microparticles with similar atomic sizes and the same crystal structure types. In this paper,

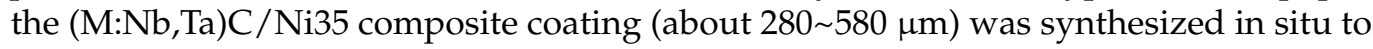
reinforce the thin coating cladded on $40 \mathrm{Cr}$ steel. The effects of ceramic micro-particle content on the phase composition and microstructure of the composite coating, as well as the structural characteristics and formation mechanism of $(\mathrm{M}: \mathrm{Nb}, \mathrm{Ta}) \mathrm{C}$, were explored systematically. In addition, the tribological mechanism and electrochemical corrosion behavior of the composite coating were described in detail.

\section{Experimental Procedure}

\subsection{Materials and Methods}

The $40 \mathrm{Cr}$ steel $(150 \times 150 \times 8 \mathrm{~mm})$ was utilized as a base material, with the chemical composition of C 0.4, Mn 0.6, Si 0.27, Cr 1.1, Cu 0.2, Ni 0.2 and Fe balanced (wt.\%). The steel surface was polished, cleaned and blow dried, in succession. The reinforcement layer material was $\mathrm{Nb} / \mathrm{Ta}$ /graphite/Ni35 alloy mixed powder, and the average particle sizes were $20 \mu \mathrm{m}, 40 \mu \mathrm{m}, 20 \mu \mathrm{m}$ and $50 \mu \mathrm{m}$, respectively. The purity of $\mathrm{Nb}$, Ta and C were all $99.9 \%$, and the chemical composition of Ni35 was C 0.3, B 2.0, Si 3.0, Cr 8.5, Fe 3.0 and Ni balanced (wt.\%).

The process parameters for preparing the composite coating are shown in Table 1. In the $\mathrm{Nb}-\mathrm{Ta}-\mathrm{C} / \mathrm{Ni} 35$ mixed powder, the weight percentage of $\mathrm{Ta}: \mathrm{Nb}: \mathrm{C}$ was $1: 1: 2$. Ta- $\mathrm{Nb}-\mathrm{C}$ and Ni35 respectively increased and decreased by $3 \%$ through weight percentage (numbered S1 S6). The preset thickness of S1 was set to $350 \mu \mathrm{m}$ to prepare a thin coating. Six groups of powders in different proportions were mixed by a planetary ball mill and dried in a drying oven at $60^{\circ} \mathrm{C}$ for $2 \mathrm{~h}$. Finally, a layer of Ta-Nb-C/Ni35 powder mixed with a small number of adhesive (polyvinyl alcohol glue) was pre-placed on the steel surface by the preset method, and the laser cladding test was performed after $3 \sim 5 \mathrm{~h}$ at $25^{\circ} \mathrm{C}$.

Table 1. Processing parameters of composite coating with different ceramic micro-particles.

\begin{tabular}{cccc}
\hline No. & Nb:Ta:C (wt.\%) & Nb-Ta-C (wt.\%) & Ni35 (wt.\%) \\
\hline S1 & 0 & 0 & 100 \\
S2 & $1: 1: 2$ & 3 & 97 \\
S3 & $1: 1: 2$ & 6 & 94 \\
S4 & $1: 1: 2$ & 9 & 91 \\
S5 & $1: 1: 2$ & 12 & 88 \\
S6 & $1: 1: 2$ & 15 & 85 \\
\hline
\end{tabular}

IPG-2000 continuous wave laser was employed as cladding equipment, with a maximum output power of: $2000 \mathrm{~W}$, laser wavelength: $1064 \mathrm{~nm}$, spot diameter: $2 \mathrm{~mm}$ and focal length: $12 \mathrm{~mm}$. In this experiment, the optimized laser processing parameters were selected based on the first experiment, which includes output power: $600 \mathrm{~W}$, scanning speed: $500 \mathrm{~mm} / \mathrm{min}$, overlap ratio between adjacent channels: $50 \%$ and argon shielding gas flow rate: $10 \mathrm{~L} / \mathrm{min}[12]$.

\subsection{Microstructural Characterization}

The (M:Nb,Ta)C $/ \mathrm{Ni35}$ composite coating was subjected to wire cutting $(12 \times 6 \times 8 \mathrm{~mm})$ and polishing with sandpaper of 180, 600, 1000, 1500 and 2000 meshes, respectively. Aqua regia $\left(\mathrm{V}_{\mathrm{HCl}}: \mathrm{V}_{\mathrm{HNO}}=3: 1\right)$ was employed to perform metallographic corrosion on the pol- 
ished surface of the samples. X-ray diffractometer (XRD) with copper $\mathrm{K} \alpha$ radiation was used to identify the phase composition, which included scanning range: $30 \sim 92^{\circ}$ and scanning speed: $1 \%$ min. The optical microscope $(\mathrm{OM})$ and the scanning electron microscope (SEM, Hitachi S-3400N, Hitachi Company, Tokyo, Japan) equipped with an energy dispersive spectrometer (EDS, Hitachi S-3400N, Hitachi Company, Tokyo, Japan) were utilized to observe the microstructure of the samples.

\subsection{Mechanical Tests}

The friction and wear tests were performed on the samples $(20 \times 20 \times 8 \mathrm{~mm})$ by using HT-1000G high-temperature friction and wear tester. The wear test was prepared with a load of $5 \mathrm{~N}$ and a speed of $560 \mathrm{r} / \mathrm{min}$, using a GCr15 steel friction ball ( $\Phi 5 \mathrm{~mm}, 60 \mathrm{HRC})$. The test was performed for $20 \mathrm{~min}$ with a wear scar radius of $2 \mathrm{~mm}$. During the test, the wear morphology was observed to understand the wear mechanism.

Through the CHI 660 electrochemical workstation (CHI 660E, Chenhua Company, Shanghai, China), a three-electrode system was utilized for an electrochemical corrosion test of the sample $(10 \times 10 \times 2 \mathrm{~mm})$ at $25^{\circ} \mathrm{C}$. The main parameters include saturated calomel electrode, Pt electrode, working electrode (S0 S6, S0 was the matrix) and neutral $3.5 \% \mathrm{NaCl}$ electrolyte. The polished $10 \times 10 \mathrm{~mm}$ coating surface was exposed as the working surface, and the rest was sealed with epoxy resin. Before the experiment, the sample was immersed in $\mathrm{NaCl}$ solution for $30 \mathrm{~min}$ to obtain a stable open circuit potential $\left(\mathrm{E}_{\mathrm{OCP}}\right)$. In the frequency range from $10^{5} \mathrm{~Hz}$ to $10^{-2} \mathrm{~Hz}$, an electrochemical impedance spectroscopy (EIS, CHI 660E, Chenhua Company, Shanghai, China) was performed at $\mathrm{E}_{\mathrm{OCP}}$ with an alternate current signal of $5 \mathrm{mV}$ RMS.

\section{Results and Discussion}

\subsection{Phase Composition of Composite Coating}

Figure 1 depicts the XRD results of composite coating with different ceramic microparticle content. The results show that the slender and sharp diffraction peaks of $\mathrm{S} 1$ on the crystal planes of (111), (200), (220) and (311) are indexed to $\mathrm{Cr}_{0.19} \mathrm{Fe}_{0.7} \mathrm{Ni}_{0.11}, \mathrm{Fe}_{0.64} \mathrm{Ni}_{0.36}$, $(\mathrm{Fe}, \mathrm{Ni})$, and (111), (200) and (220) correspond to $\mathrm{Cr}$, as shown in Figure 1a. When a small number of ceramic micro-particle was added $(3 \mathrm{wt} . \%)$, the intensity of the diffraction peaks changes slightly, see Figure $1 \mathrm{~b}$. The new weak diffraction peaks at $2 \theta$ angles of $35.022^{\circ}, 58.599^{\circ}$ and $73.393^{\circ}$ show the appearance of $(\mathrm{M}: \mathrm{Nb}, \mathrm{Ta}) \mathrm{C}$ phase corresponding to the (111), (220) and (222) crystal planes, indicating that (M:Nb, Ta) C is synthesized in situ. The $(\mathrm{M}: \mathrm{Nb}, \mathrm{Ta}) \mathrm{C}$ has a great influence on the microstructure, resulting in the diffraction peaks along the (111), (200), (220) and (311) of the crystal plane, all to be weakened. When adding a large number of ceramic micro-particles (15 wt.\%), the intensity of the diffraction peaks obviously changes, see Figure 1c. Comparing Figure 1a,b, the diffraction peaks along the (111), (200), (220) and (311) crystal planes all continue to weaken, indicating that the increase of ceramic micro-particles causes the change of the microstructure. New diffraction peaks appearing at $45.872^{\circ}$ and $49.122^{\circ}$ are indexed to the compounds $\mathrm{Ni}_{3} \mathrm{C}$ and $\mathrm{Fe}_{3} \mathrm{C}$, respectively. In addition, the diffraction peaks are enhanced at $35.022^{\circ}, 58.599^{\circ}$ and $73.393^{\circ}$, and new diffraction peaks appear at $40.605^{\circ}, 69.997^{\circ}$ and $87.392^{\circ}$, corresponding to (200), (311) and (400) crystal planes of the (M:Nb,Ta)C phase. It can be inferred that more (M:Nb,Ta)C are synthesized in situ. After the in situ synthesis of $(\mathrm{M}: \mathrm{Nb}, \mathrm{Ta}) \mathrm{C}$, the remaining $\mathrm{Nb}-\mathrm{Ta}$ combined with $\mathrm{Ni}$ to form $\mathrm{NbNi}$ and $\mathrm{NiTa}$, and the diffraction peak was observed at $77.923^{\circ}$. In Figure $1 b, c$, there are gradually reinforced diffraction peaks at $50.668^{\circ}$, which are indexed as $\mathrm{Cr}_{23} \mathrm{C}_{6}$. This is attributed to the "Cr-poor phenomenon". The $\mathrm{Cr}$ in the matrix and powder is easily combined with higher content of graphite to produce chromium carbide and precipitate to the grain boundary. 
(c)

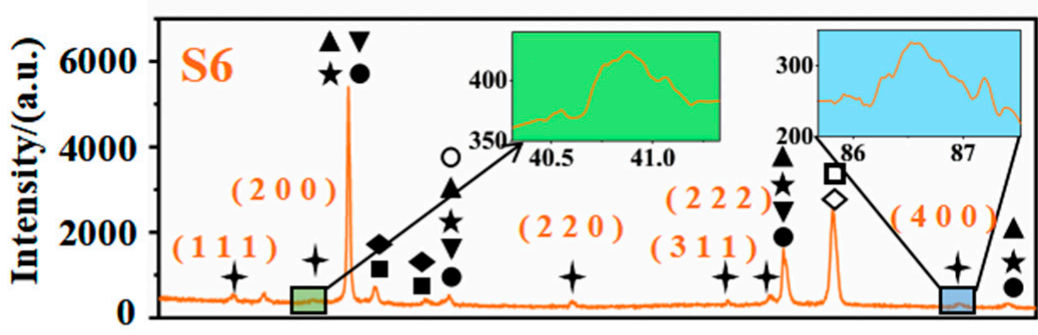

(b)

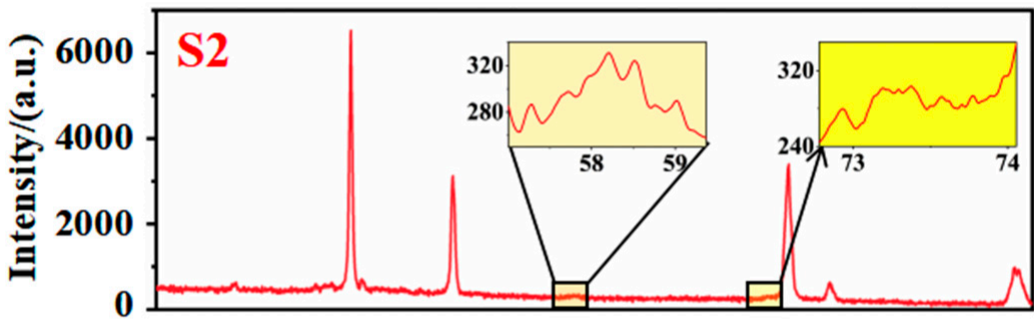

(a)

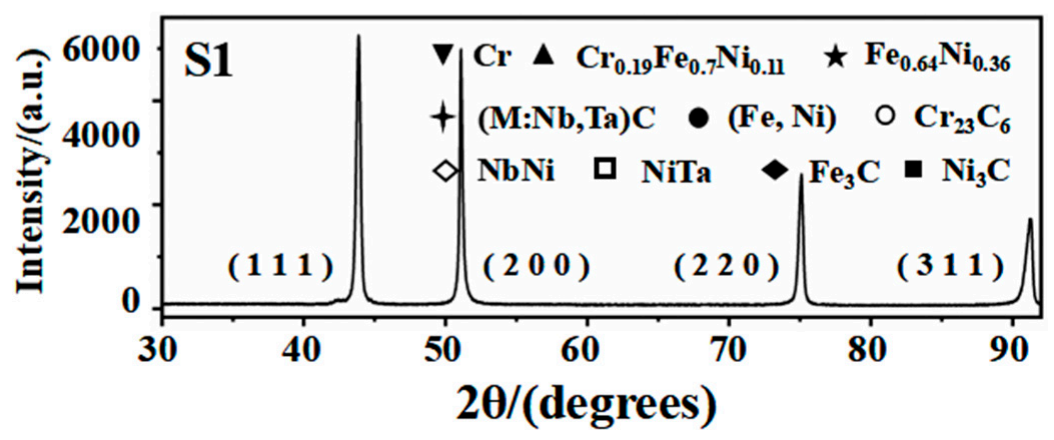

Figure 1. XRD results of composite coating with different ceramic micro-particle content (a) S1; (b) S2; (c) S6.

Additionally, when comparing Figure $1 \mathrm{a}-\mathrm{c}$, the position of the strong peak is observed to shift toward the left, resulting in a corresponding decrease in the $2 \theta$ value. On the one hand, according to the Bragg Equation (1) [13]:

$$
2 d \sin \theta=n \lambda
$$

where $\lambda$ is the wavelength, $n$ is the reflection series, $d$ is the interplanar crystal distance, $\theta$ is the angle between the incident ray and the reflected line. The decrease of the $2 \theta$ represents an increase in the $d$. Some alloying elements (such as $\mathrm{Nb}, \mathrm{Ta}, \mathrm{C}$ and $\mathrm{Si}$ ) and their compounds precipitate, nucleate and grow among the crystal grains during solidification. On the other hand, some alloying elements precipitated too late remain in the crystal lattice, resulting in a slight distortion of the crystal lattice [14].

\subsection{Microstructure Evolution of Composite Coating}

Figure 2a-f show the cross-sectional morphology change of composite coating with different ceramic micro-particle content. There is a good metallurgical bond between the thin coating and the matrix without obvious defects, such as cracks and pores. The thickness of the thin coating without ceramic micro-particles (Figure 2a) was the smallest (only $284 \mu \mathrm{m}$ ), with a relatively flat bonding interface, appearing as the directional solidification and slender columnar dendrites at the bottom of the molten pool. The powder with a smaller particle size has a higher absorption rate to laser energy, causing a smaller matrix melting, a low dilution rate and a smooth bonding interface. Figure $2 b, c$ display that the thickness of composite coating with a small number of ceramic micro-particle increase and the columnar dendrites are slightly smaller. 


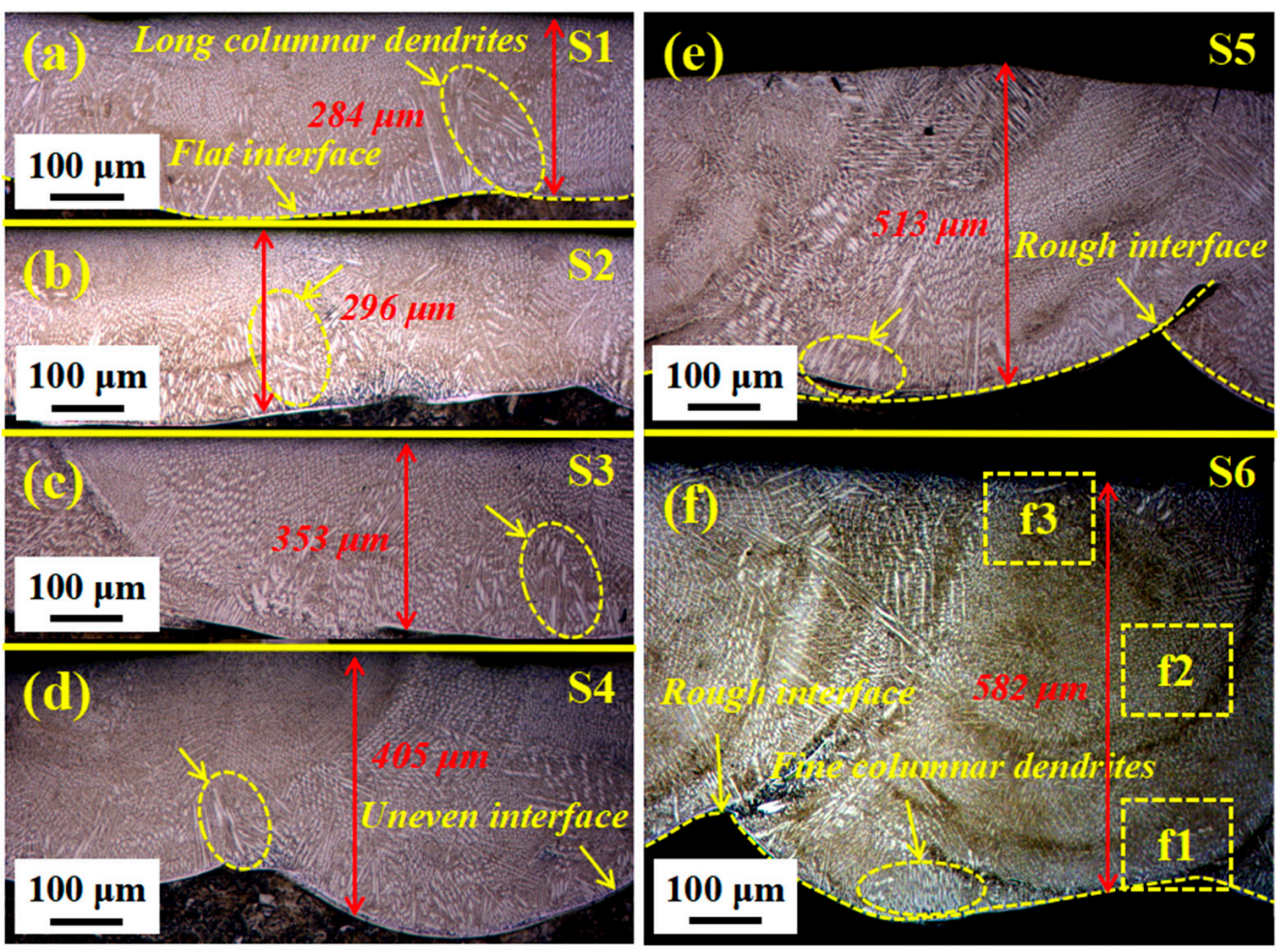

Figure 2. Typical OM diagram of a cross-section of composite coating with different ceramic microparticle content. (a) S1; (b) S2; (c) S3; (d) S4; (e) S5; (f) S6.

Further increasing the ceramic micro-particle content (Figure 2d), the thickness of the composite coating and the curvature of the bonding interface significantly increase, presented as a clear wave shape, and the columnar dendrites continue to shrink. Graphite with a larger volume and ceramic micro-particles with a smaller particle sizes have a larger specific surface area and higher nucleation rate, which plays a role in refining the structure. Moreover, it is inhibited by more in situ synthesis enhanced phases, and the large-volume mixed powder absorbs less laser energy to form a higher thickness coating. However, the heat dissipation conditions at the bottom of the molten pool with highthickness coatings are worse, especially the high-energy area of the Gaussian spot. This allows the temperature to be maintained for a period to delay solidification and melt the matrix, which manifests as a high-curvature bonding interface. When more ceramic micro-particles are added (Figure 2e,f), the coating thickness increases even more (up to $582 \mu \mathrm{m})$ with uneven bonding interfaces and the smallest dendrites.

The high-magnification OM diagrams of the bonding interface between the matrix and the coating was taken and observed to have good metallurgical bonding characteristics in Figure 3a-(f1). Additionally, the different areas of S6 in Figure $2 \mathrm{f}$ are magnified in Figure 3(f1-f3). The bottom of the molten pool is composed of columnar and equiaxed dendrites. The middle part is mainly columnar, cellular and equiaxed dendrites, while the top part is dominated by columnar and cellular dendrites. 

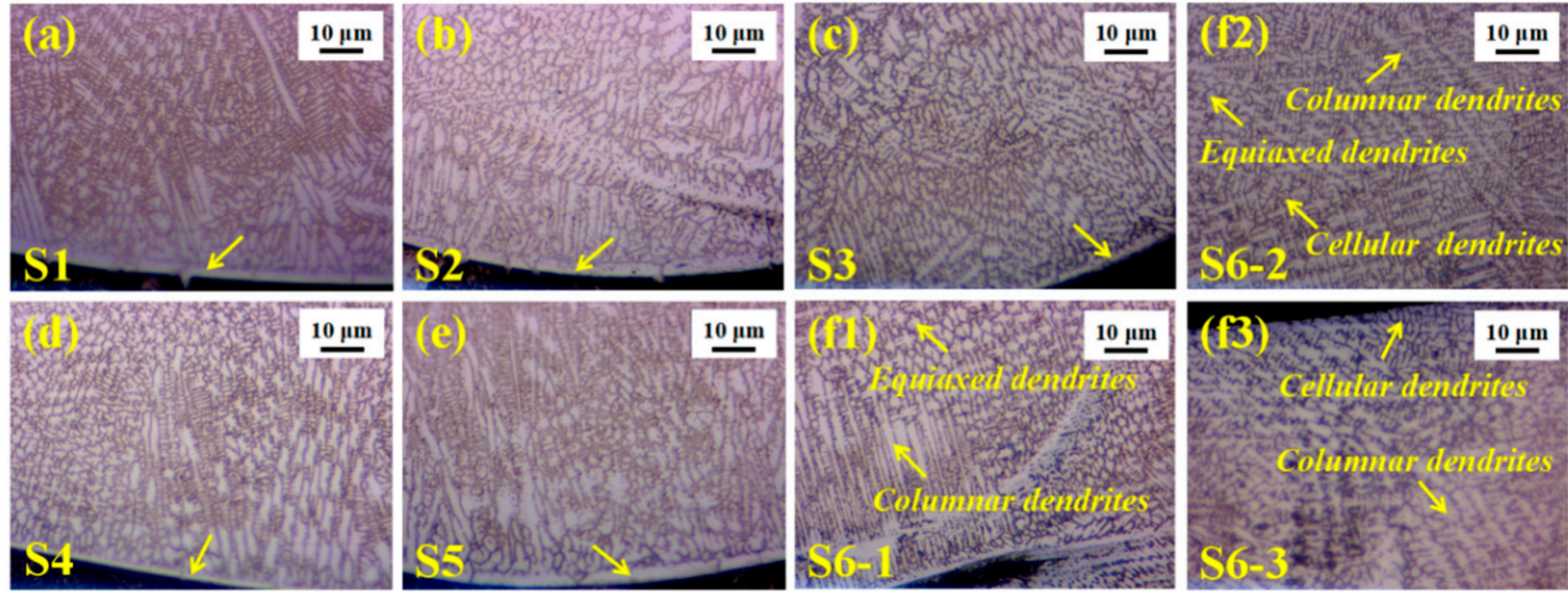

Figure 3. The high-magnification OM diagrams of the bonding interface and the different areas of S6. (a) S1; (b) S2; (c) S3; (d) S4; (e) S5; (f1) S6 (the bottom); (f2) the middle; (f3) the top.

\subsection{Structural Characteristics of $(\mathrm{M}: \mathrm{Nb}, \mathrm{Ta}) \mathrm{C}$}

To explore the change in the structural characteristics of the composite coating with different ceramic micro-particle content, the SEM images are shown in Figure 4. Figure 4a shows the morphology of Ni35 powder cladded on $40 \mathrm{Cr}$ steel. The crystal grains grow in an orderly manner with sizes between $3 \sim 5 \mu \mathrm{m}$, and the grain boundaries are round and smooth. The grain boundaries with a small number of ceramic micro-particles are deformed (Figure $4 \mathrm{~b}, \mathrm{c}$ ), and some sub-micron white granular phases are evenly distributed along the grain boundaries without regular geometric shape. The irregular arrangement of atoms at the grain boundary, with defects, such as holes and dislocations, is conducive to the diffusion of the strong carbide-forming elements, $\mathrm{Nb}-\mathrm{Ta}$, with a larger atomic radius. Additionally, $\mathrm{Nb}-\mathrm{Ta}$ can reduce the high energy of grain boundary atoms due to deviation from the equilibrium position, resulting in preferential diffusion to the grain boundary. The density of $\mathrm{Nb}$ is equivalent to that of $\mathrm{Ni}$, which plays a role in dispersing and evenly distributing. When the ceramic micro-particle content approaches $9 \mathrm{wt} . \%$ (Figure $4 \mathrm{~d}$ ), the particles grow into a spherical shape with a size of about $0.3 \mu \mathrm{m}$. In Figure $4 \mathrm{e}$, the grain boundary deformation gradually deepens. The particles gradually grow into micron-level regular geometric shapes, such as quadrilaterals, hexagons, and polyhedrons, causing the abnormal aggregation phenomenon (reverse diffusion). More ( $\mathrm{M}: \mathrm{Nb}, \mathrm{Ta}) \mathrm{C}$ is synthesized in situ and serves as the core of heterogeneous crystals, which acts as a pin to hinder crystal grain growth and cause grain boundary deformation.

Moreover, $\mathrm{Nb}-\mathrm{Ta}$ is hard to enter the lattice gap or replace $\mathrm{Fe}$ to form a solid solution and distribute it along the grain boundaries. The alloying elements separation at the grain boundaries also reduces the system's energy [15]. As the ceramic micro-particle content increases (15 wt.\%), the cluster particles grow further into petal shapes with sizes of $4 \mu \mathrm{m}$ and the crystal grains are also refined to $1 \sim 2 \mu \mathrm{m}$, see Figure $4 \mathrm{f}$. Because convective flow initiates the collision and assembly of particles in the molten state, some particles are engulfed by the continuously advancing solid-liquid interface [16]. Furthermore, the larger atomic size of $\mathrm{Nb}$-Ta preferentially occupies the grain boundary position, which reduces the interface energy and inhibits the grains growth [17]. 

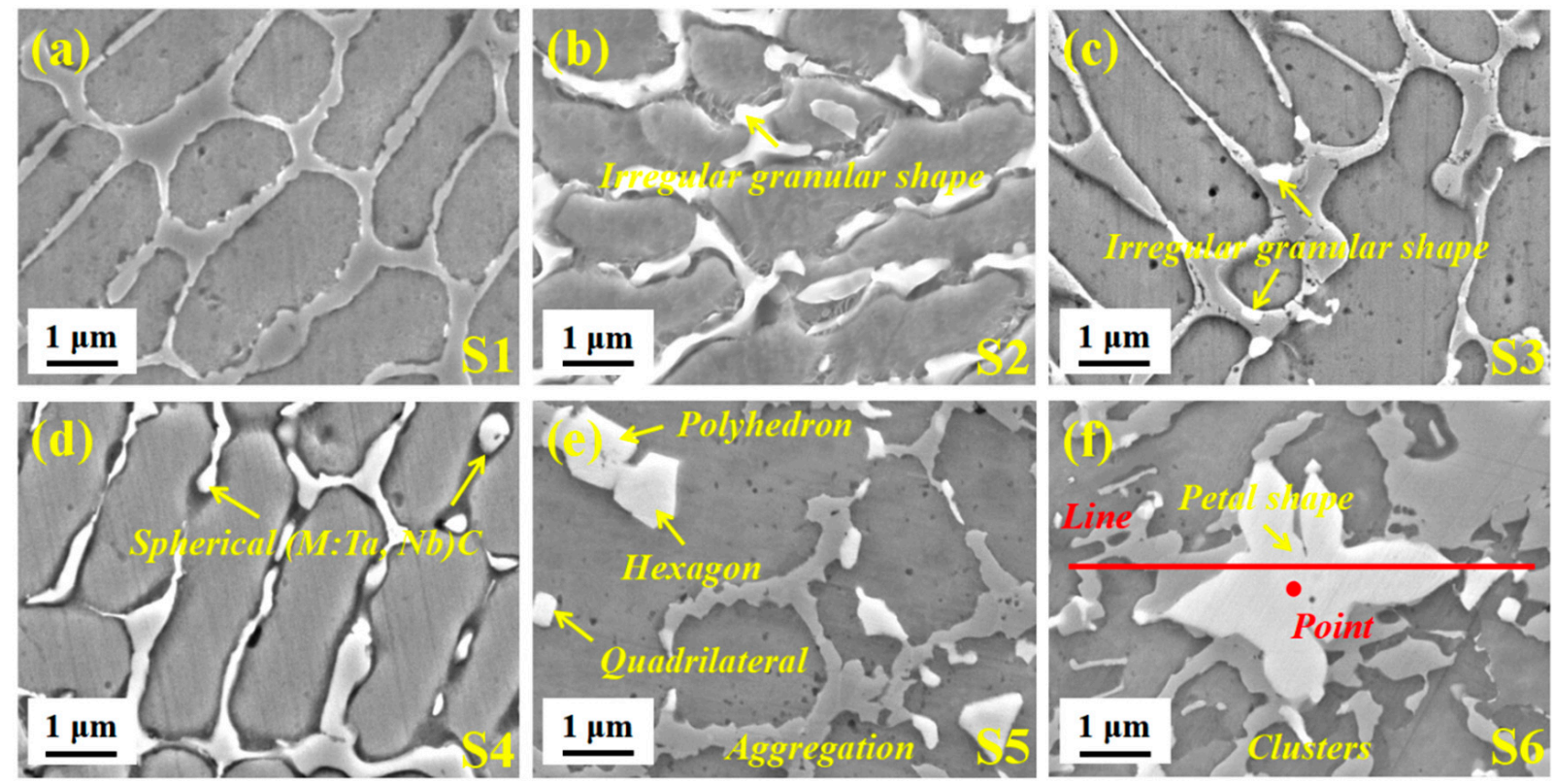

Figure 4. Typical SEM images of composite coating with different ceramic micro-particle content. (a) S1; (b) S2; (c) S3; (d) S4; (e) S5; (f) S6.

To further explore the distribution of elements in the composite coating, a EDS line profile on S6 was performed, as shown in Figure 5. The main alloying elements, Fe and Ni, are evenly distributed throughout the composite coating. The content of $\mathrm{Fe}$ and $\mathrm{Ni}$ where the curve does not pass through the white phase increases and decreases alternately. Since the $\mathrm{Fe}-\mathrm{Ni}$ alloy undergoes grain boundary segregation during solidification, the solute atom $\mathrm{Ni}$ is continuously discharged from the solid phase to the liquid phase, resulting in a large number of $\mathrm{Ni}$ in the final solidified grain boundary part. The white phase is identified as $\mathrm{Nb}-\mathrm{Ta}$ elements, confirming that $(\mathrm{M}: \mathrm{Nb}, \mathrm{Ta}) \mathrm{C}$ particles are synthesized in situ.

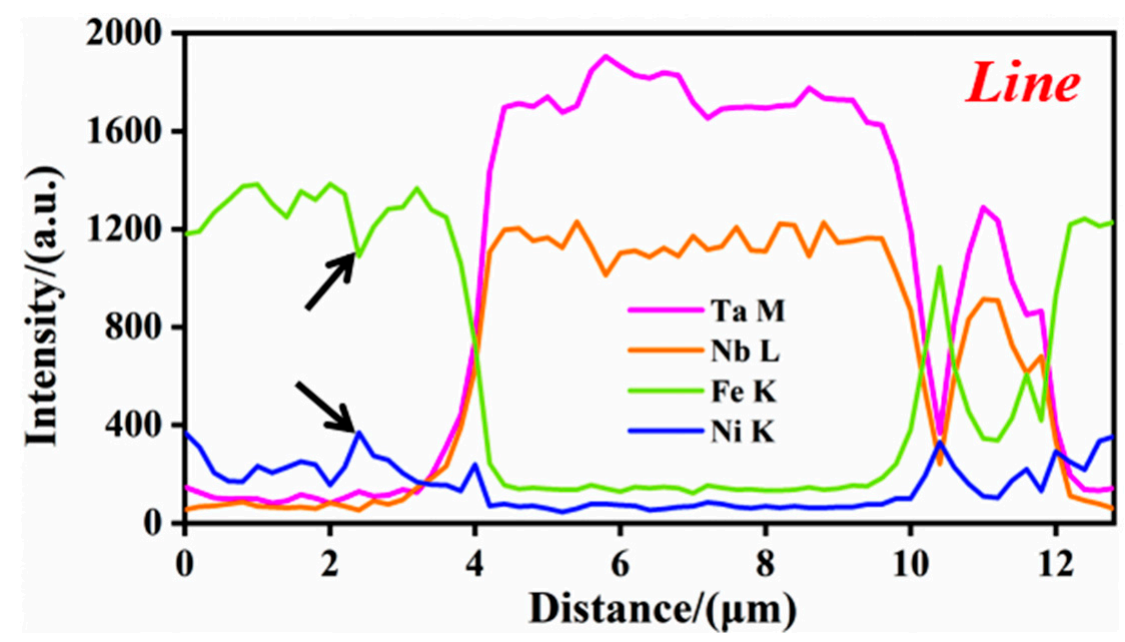

Figure 5. The EDS line profile of element concentration in the typical area in Figure 4.

Moreover, the intensity of the large-size white phase is more extensive, indicating a higher degree of element aggregation. Combined with the point analysis of the white phase in Figure 6, the results show that the content of $\mathrm{Nb}-\mathrm{Ta}$ and $\mathrm{C}$ is high, which again verifies the synthesis of $(\mathrm{M}: \mathrm{Nb}, \mathrm{Ta}) \mathrm{C}$ particles. However, it is worth noting that the $\mathrm{C}$ content is not the highest. 


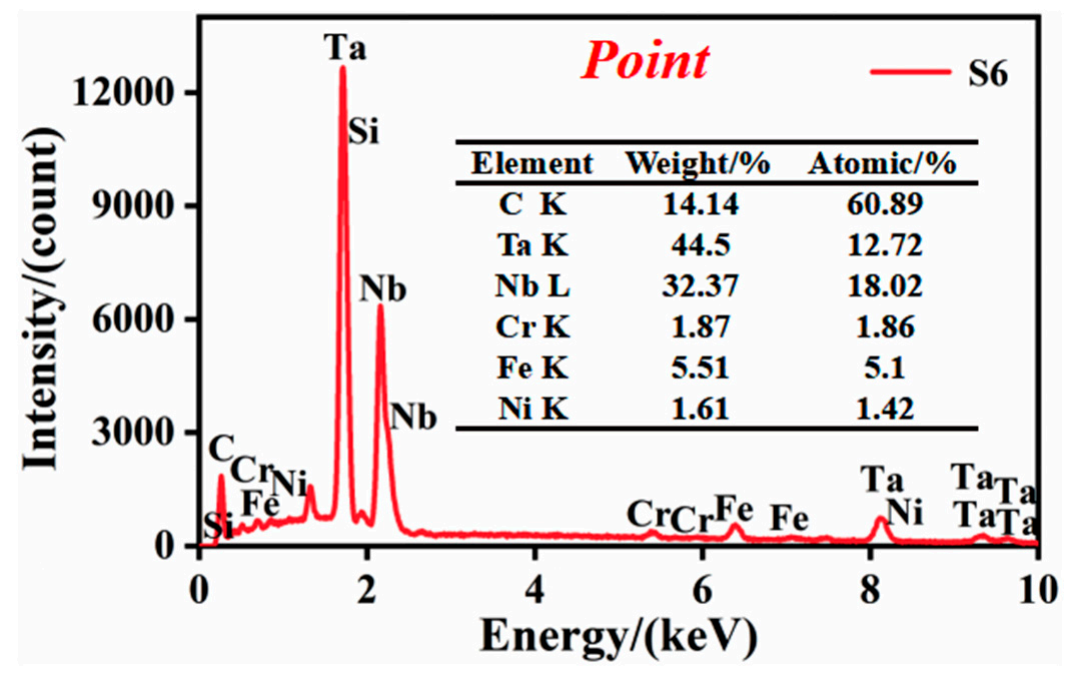

Figure 6. The point analysis of element concentration of the point in Figure 4.

To explore the overall distribution of the remaining $\mathrm{C}$ and $\mathrm{Nb}-\mathrm{Ta}$, the area mapping was performed on S6, as shown in Figure 7. Figure 7a,b are the field of view and overlay of S6, respectively, which straightforwardly illustrates the overall distribution of each element. In Figure 7c,d, C and Cr are mainly concentrated in the white phase, followed by grain boundaries, because $C$ with a small atomic radius cannot be entirely dissolved by the strong carbide forming elements, $\mathrm{Nb}$-Ta. According to the atomic diffusion theory, small interstitial solute atoms $C$ easily migrate from one interstitial position of the lattice to another [18]. The loose structure in the grain boundary becomes a channel for the rapid diffusion of $C$, forming the phenomenon of grain boundary segregation. In addition, the above-mentioned Cr easily follows C distribution to form a "Cr-poor phenomenon", including the white phase and the precipitation at the grain boundary. In Figure 7e-h, the intensities of $\mathrm{Nb}$-Ta in the petal shape and scattered granular white phases are much higher than that in other regions. In contrast, the intensities of Fe and $\mathrm{Ni}$ are extremely low, indicating that they are mainly distributed in areas other than at the white phase. Additionally, referring to the previous report $[19,20]$, the white phase is synthesized in situ; $(\mathrm{M}: \mathrm{Nb}, \mathrm{Ta}) \mathrm{C}$ has been further determined.
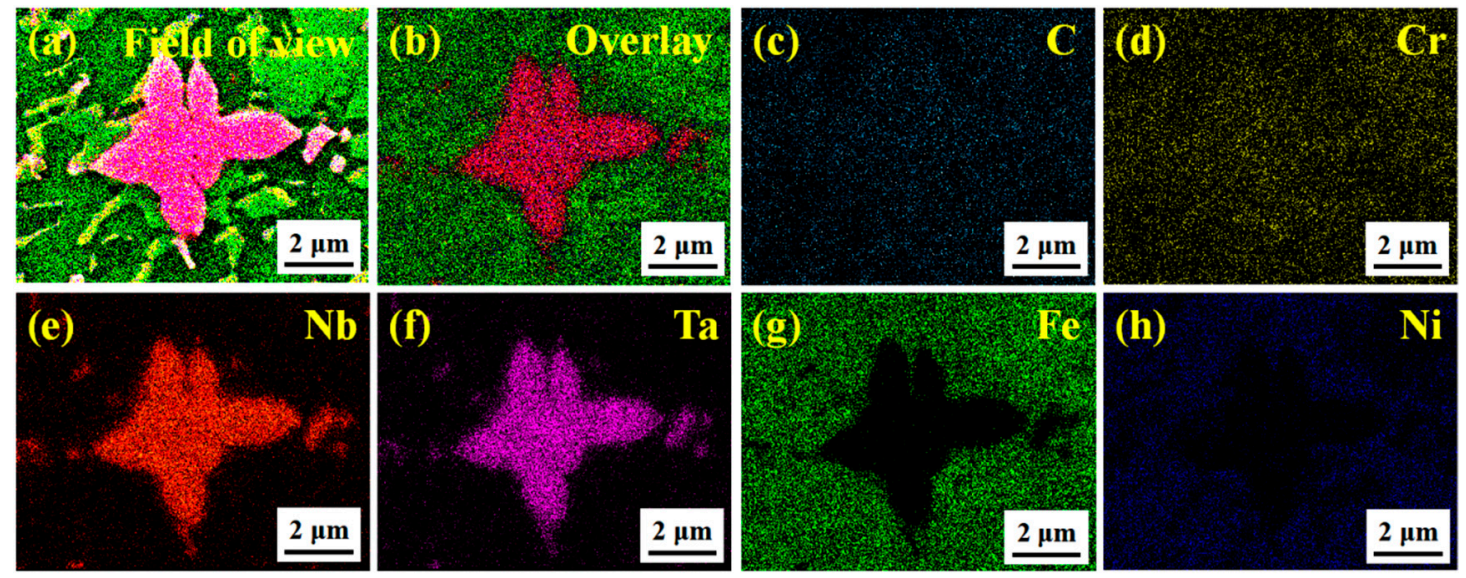

Figure 7. Typical area mapping of S6 in Figure 4. (a) Field of view; (b) overlay; (c) C; (d) Cr; (e) Nb; (f) Ta; (g) Fe; (h) Ni.

Figure 8 is schematic diagrams of the cross-sectional structure change and heat dissipation. Viewed from the top of the matrix, the circular laser spot is continuously output to form a multi-melt lap, corresponding to the cross-sectional structure change and the heat dissipation. With the increase of the ceramic micro-particle content, the thickness of the composite coating increases and heat dissipation capacity weakens, causing a gradually 
increasing curvature of the bonding interface. Additionally, the changes of $(\mathrm{M}: \mathrm{Nb}, \mathrm{Ta}) \mathrm{C}$ morphology (irregular granular, spherical, polyhedral and petal shape), size (sub-micron and micron) and number (increased) continuously inhibits the growth of crystal grains. $\mathrm{S} 1$ means that it does not contain any composite carbides and the $(\mathrm{M}: \mathrm{Nb}, \mathrm{Ta}) \mathrm{C}$ form is a small amount of irregular granular in S2. S4 indicates that the white phase grows into a spherical shape and even a polyhedron in S5. However, some of the white phases appear to be clustered into micron-sized petal shapes in S6.

(a)

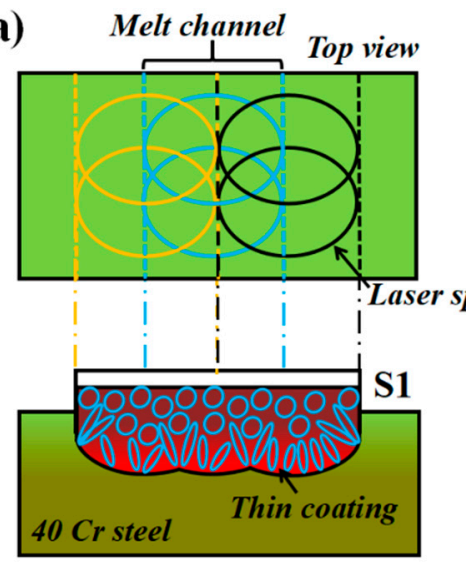

(b)

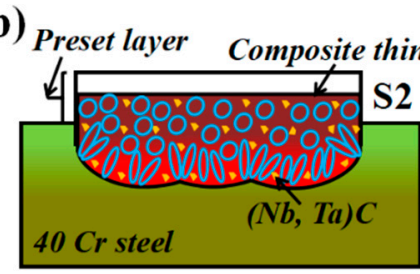

(c)

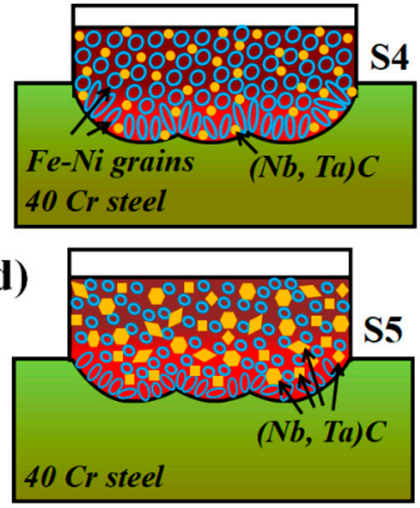

(e)

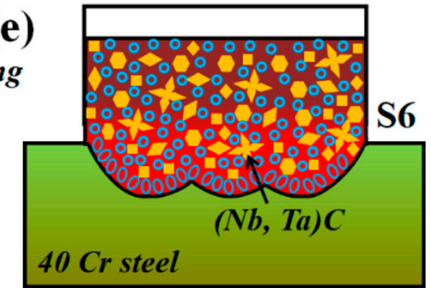

Figure 8. Schematic diagrams of cross-sectional structure change and heat dissipation of composite coating with different ceramic micro-particles. (a) S1; (b) S2; (c) S4; (d) S5; (e) S6.

\subsection{Formation Mechanism and Morphological Change of (M:Nb,Ta)C}

The formation mechanism and morphological changes of $(\mathrm{M}: \mathrm{Nb}, \mathrm{Ta}) \mathrm{C}$ particles are summarized. In the molten state, $\mathrm{Nb}-\mathrm{Ta}$ and $\mathrm{C}$ with very different atomic radii tend to form interstitial solid solutions of $\mathrm{NbC}$ and $\mathrm{TaC}$. Additionally, $\mathrm{Nb}-\mathrm{Ta}$ with very similar atomic radii $(0.1429 \mathrm{~nm}$ and $0.1430 \mathrm{~nm}$, respectively) can replace each other to form ( $\mathrm{M}: \mathrm{Nb}, \mathrm{Ta}) \mathrm{C}$ substitutional solid solutions. Both of the two components of the FCC stacked crystal structure have significant solubility. When the temperature drops to the melting point of the solid solution, the $(\mathrm{M}: \mathrm{Nb}, \mathrm{Ta}) \mathrm{C}$ atom clusters and the attached impurity particles in the liquid phase become crystal embryos of homogeneous nucleation and heterogeneous nucleation. Subsequently, during the random growth of embryos, $\mathrm{NbC}, \mathrm{TaC}$ and $(\mathrm{M}: \mathrm{Nb}, \mathrm{Ta}) \mathrm{C}$ are attached to form a coherent phase boundary with small elastic distortion. During this process, the inter-lattice diffusion of interstitial atoms $C$ and the substitution between adjacent atoms of $\mathrm{Nb}-\mathrm{Ta}$ occur.

When adding fewer ceramic micro-particles, the $(\mathrm{M}: \mathrm{Nb}, \mathrm{Ta}) \mathrm{C}$ grains with less epitaxial layers in the normal direction grow smaller, which are easy to collide and assemble under convection action, appearing as sub-micron irregular granular shapes. With the increase of the ceramic micro-particle, the crystal grains with more epitaxial layers grow to the micron level. Meanwhile, the host elements $\mathrm{Fe}$ and Ni have begun to crystallize at the continuously decreasing temperature. Under the obstacle of the grain and the phase boundary, the convective motion slows down, causing the collision to have little impact on the crystal grains. The crystal grains begin to grow into spherical, polyhedral and petal shapes along the direction of the lowest surface energy of the crystal ((111) plane) until the end of solidification $[14,21]$. 


\subsection{Friction and Wear Test}

Figure 9 depicts the friction coefficient (COF) curves. In general, the COF does not stop increasing at the initial friction stage until the stable stage. However, the entry time and the coefficient value are different. Although the COF of S0 is low, it has been in a slow-rising stage for a long time until $900 \mathrm{~s}$. The wear morphology in Figure 10a shows that there is a wide and discontinuous furrow-like morphology on S0 with a large amount of oxidized flaking debris attached. During severe friction, the hard carbides in the GCr15 steel ball material fall off and remain on the contact surface, causing loose scratches and easy oxidation to produce abrasive wear. The COF of the thin coating (S1) without adding ceramic micro-particles is the largest and the time to stabilize is still very long (about $500 \mathrm{~s}$ ). In addition, the wear width is also the largest (about $875 \mu \mathrm{m}$ ) and there is a large area of flaking caused by plastic tearing. The wear resistance of the Ni-based thin coating has not improved much, which is mainly attributed to the low thickness of the preset powder.

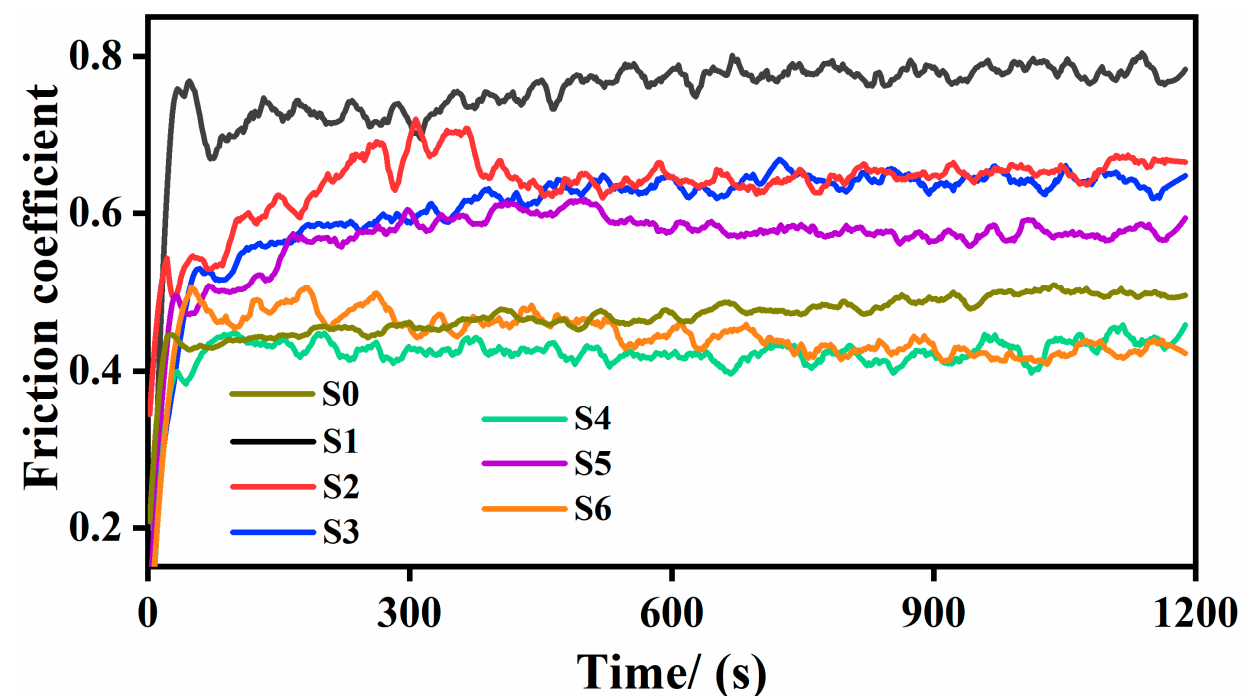

Figure 9. Friction coefficient curves of composite coating with different ceramic micro-particles.
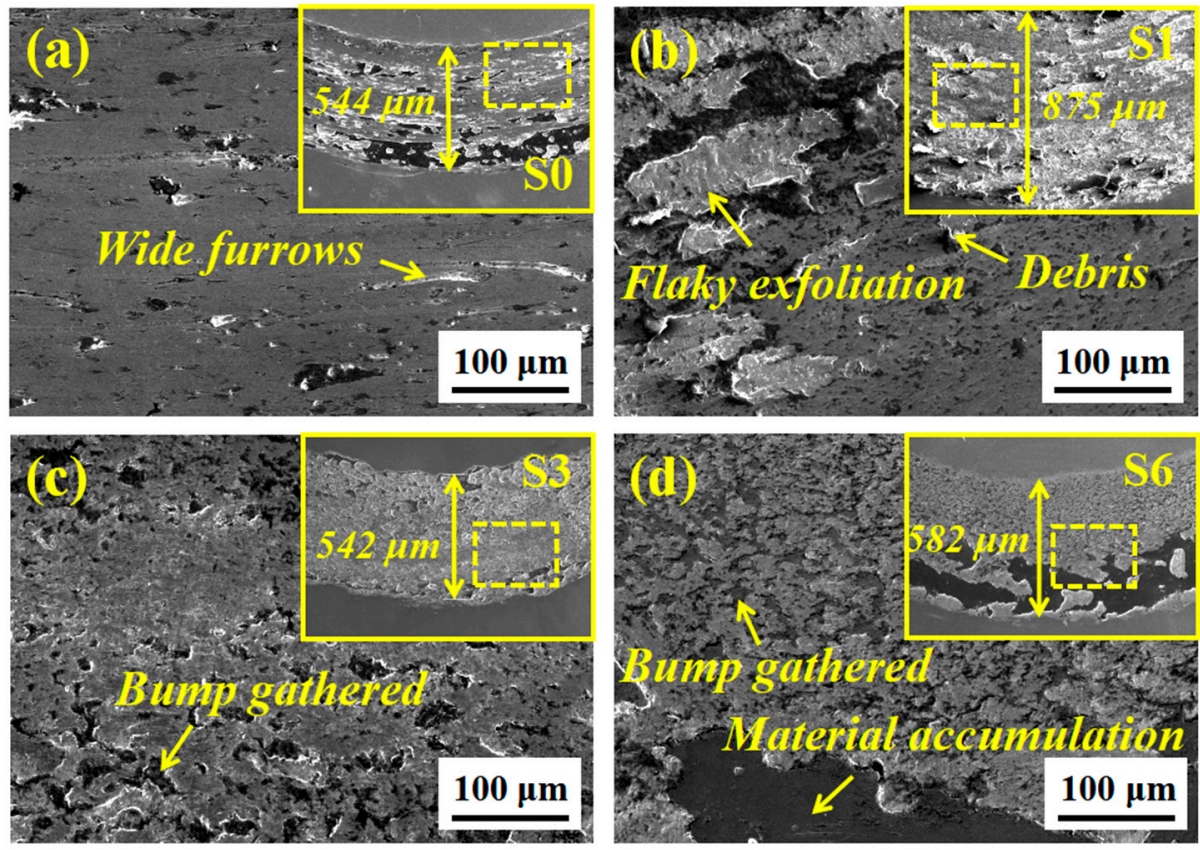

Figure 10. Typical SEM diagrams of the wear morphology of composite coating with different ceramic micro-particle. (a) S0; (b) S1; (c) S3; (d) S6. 
Additionally, the relative sliding between the GCr15 steel ball material and the parent material causes shear at the contact point, leading to the destruction of the surface film and the occurrence of adhesive wear. When adding fewer ceramic micro-particles ( $3 \mathrm{wt} . \%$ and $6 \mathrm{wt} . \%$ ), the COF decreases slightly, and the stabilize time continues to shorten (about $400 \mathrm{~s}$ ). Nevertheless, in the initial stage, the curve of S2 fluctuates the most, indicating that the friction process is the most intense. Moreover, the wear width of S3 is reduced (about $550 \mu \mathrm{m}$ ) and the wear surface is improved significantly. However, there is a protrusion-gathering phenomenon of oxidization at intervals, especially on both sides of the rubbing direction.

On the one hand, the $(\mathrm{M}: \mathrm{Nb}, \mathrm{Ta}) \mathrm{C}$ in the parent material inhibits grain growth and achieves fine grain strengthening. On the other hand, loose wear debris of the parent and the GCr15 steel ball material tends to adhere to the surrounding of the exposed ( $\mathrm{M}: \mathrm{Nb}, \mathrm{Ta}) \mathrm{C}$ of high hardness during the wear process. However, some areas are hard to resist shear stress and are destroyed, forming this kind of interval phenomenon, especially in areas where the shear force is smaller on both sides. When the ceramic micro-particles exceed $9 \mathrm{wt} . \%$, the COF continues to decrease and the stabilize time is reduced to 100 200 s. Inclusively, S4 (oscillating at 0.4325) and S6 (oscillating at 0.4247) have the shortest stabilize time and the smallest COF (lower than S0), which means that the microstructures are more conducive to enhancing the wear resistance of the composite coating. It is worth mentioning that the COF of S5 is relatively larger. The microstructure determines the macroscopic properties. The polyhedral particles in S5 are small and easily fall off, acting as abrasive particles to form higher surface roughness and cause an increase of COF. The shed spherical particles in S4 have a more significant rolling lubrication effect of reducing roughness by grinding convexities and filling concaves. The interval phenomenon of S6 is more evident than others. There is a large area of material accumulation of the parent and the GCr15 steel ball in the outer ring, which is more conducive to preventing further wear of the inner coating. The bare micron-level hard phase can provide stronger attachment and shear resistance, thereby reducing the damaged area under the same shear stress. However, the accumulated material of the parent and the GCr15 steel ball in the outer ring is hard to be damaged by small shear stress and is left behind.

\subsection{Electrochemical Corrosion Test}

Figure 11 describes the potentiodynamic polarization curves and the Nyquist plots of S0 and S3 S6, and the test results are attached in Table 2. The self-corrosion potential (Ecorr) of S0 $(-0.522 \mathrm{~V})$ is smaller than that of S3 S6 $(-0.486 \sim-0.463 \mathrm{~V})$, testifying that the corrosion resistance has been improved significantly. In addition, the self-corrosion potential does not show a significant change with the increase of ceramic micro-particle contents. However, the current density of the composite coating increases first and then decreases. When the content exceeds $12 \mathrm{wt} . \%$ (S5 and S6), the polarization resistance reaches the maximum ( $3093 \Omega$ and $3559 \Omega$, respectively), and the current density reaches a minimum $\left(1.039 \times 10^{-5} \mathrm{~A} \cdot \mathrm{cm}^{-2}\right.$ and $1.065 \times 10^{-5} \mathrm{~A} \cdot \mathrm{cm}^{-2}$, respectively), which implies that they have the lowest corrosion rate and the most substantial corrosion resistance. This is consistent with the calculation of the corrosion rate in Table 2.

In Figure 11b, the arc radii of S3 S6 are larger than that of S0, and the arc radius of the sample with higher ceramic micro-particle content shows a decreasing trend after increasing. Similarly, the arc radii of S5 and S6 are relatively larger $\left(600 \Omega \cdot \mathrm{cm}^{2}\right.$ and $700 \Omega \cdot \mathrm{cm}^{2}$, respectively), which is consistent with the potentiodynamic polarization curve. Besides, although the arc radius of S4 is the largest, the current density is relatively larger, illustrating that the corrosion resistance is not the best. 

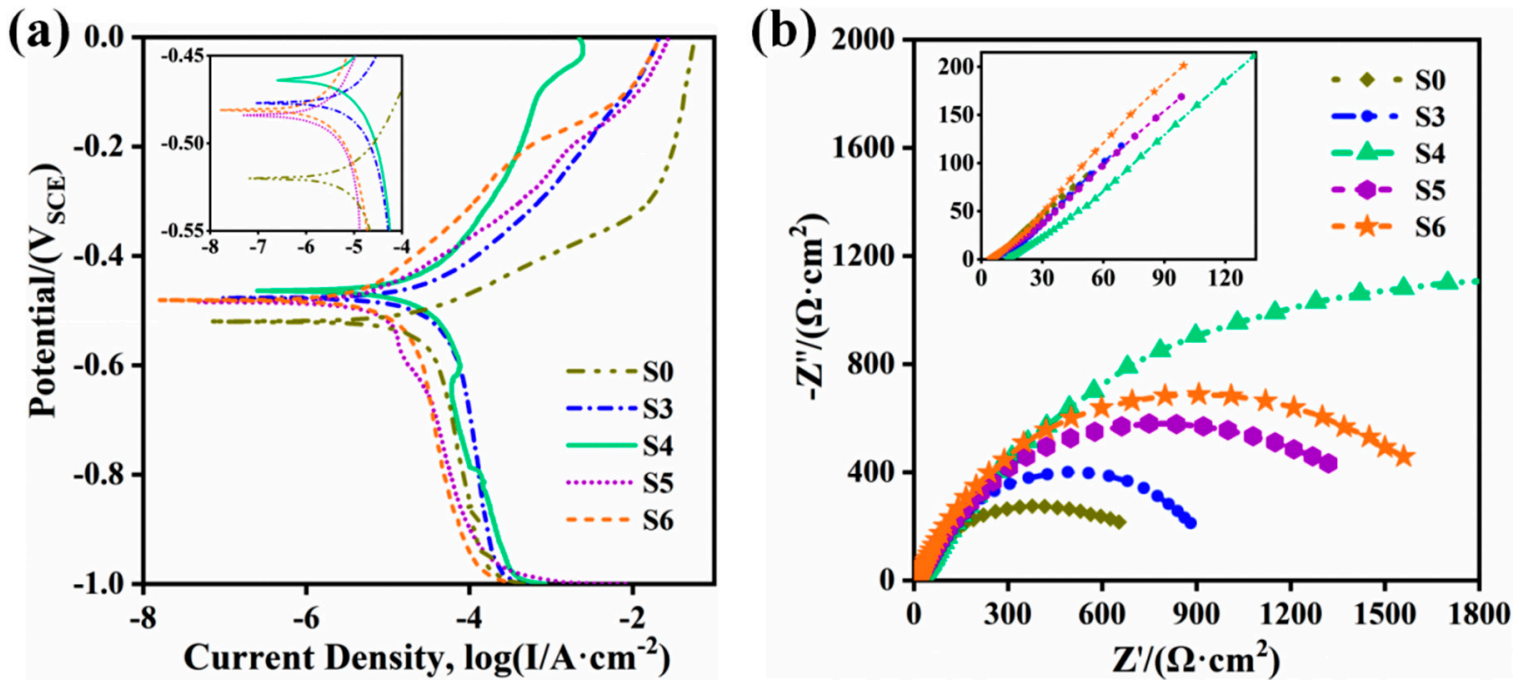

Figure 11. Potentiodynamic polarization curves and Nyquist plots of composite coating with different ceramic microparticles. (a) Potentiodynamic polarization curves; (b) Nyquist plots.

Table 2. Potentiodynamic polarization test results in Figure 11.

\begin{tabular}{ccccc}
\hline No. & $\mathbf{E}_{\mathbf{c o r r}} / \mathbf{V}$ & $\mathbf{I}_{\mathbf{c o r r}} / \mathbf{A}$ & $\mathbf{R}_{\mathbf{p}} / \mathbf{\Omega} \cdot \mathbf{c m}^{\mathbf{2}}$ & $\mathbf{V}_{\text {corr }} / \mathbf{A} \cdot \mathbf{c m}^{-\mathbf{2}}$ \\
\hline S0 & -0.522 & $2.673 \times 10^{-5}$ & 1010 & $0.932 \times 10^{-3}$ \\
S3 & -0.474 & $3.527 \times 10^{-5}$ & 1028 & $1.036 \times 10^{-3}$ \\
S4 & -0.463 & $3.676 \times 10^{-5}$ & 1289 & $0.722 \times 10^{-3}$ \\
S5 & -0.486 & $1.039 \times 10^{-5}$ & 3093 & $0.296 \times 10^{-3}$ \\
S6 & -0.479 & $1.065 \times 10^{-5}$ & 3559 & $0.286 \times 10^{-3}$ \\
\hline
\end{tabular}

To further explore the corrosion morphology, the SEM images are exhibited in Figure 12. $\mathrm{S} 0$ is severely corroded and appears with deep groove-shaped corrosion pits in Figure 12a. Corrosion occurs along the boundary of the flaky tissue, resulting in a flaky pit wall. Figure $12 \mathrm{~b}-\mathrm{f}$ show that the corrosion occurs at the grains, appearing in different sizes and depths of grain corrosion pits. The electronegativity difference between matrix and coating causes a forming of a small primary cell; therefore, corrosion mainly occurs along the depth direction perpendicular to the coating surface [22]. In addition, with the increase of ceramic micro-particle content, the size and depth of the grain corrosion pits gradually become smaller. This is attributable to the in situ synthesis of more (M:Nb,Ta)C and the continuously precipitated $\mathrm{Cr}$ element at the grain boundary, which broadens the grain boundary width and restricts the crystal grains growth, causing the porosity to continuously decrease. For S5 and S6 in particular, as shown in Figure 13, the porosity reaches the minimum $(39.89 \%$ and $22.08 \%$, respectively), which indirectly indicates the enhanced ability to resist corrosion. Meanwhile, the contact area between the crystal grains and the electrolyte, as well as the corrosion depth, is also effectively reduced to prevent further corrosion.

In Figure 12e,f, EDS element concentration analysis is performed on selected areas $A \sim D$ on the corrosion surface, and the results are shown in Table 3 . The white phase at point A shows the presence of $(\mathrm{M}: \mathrm{Nb}, \mathrm{Ta}) \mathrm{C}$ at the grain boundaries without being corroded, accompanied by oxidation. The corrosion grain pits at the black phase of point $\mathrm{B}$ also have an oxide layer, and there is also an increase in $C$ content. The $C$ content decreases in the grain boundary of point $C$. As mentioned in the previous section, $C$ is mainly concentrated in grain boundaries and composite carbides rather than crystal grains. However, there is an abnormal phenomenon that the $\mathrm{C}$ content increases at the grain pits at point $\mathrm{B}$. The essence of electrochemical corrosion is a process in which metals are oxidized through a pair of conjugated oxidation-reduction reactions. The Fe atoms in the grain pits are corroded and oxidized, causing the solid solution $\mathrm{C}$ atoms dissolved in the electrolyte to be reduced. 

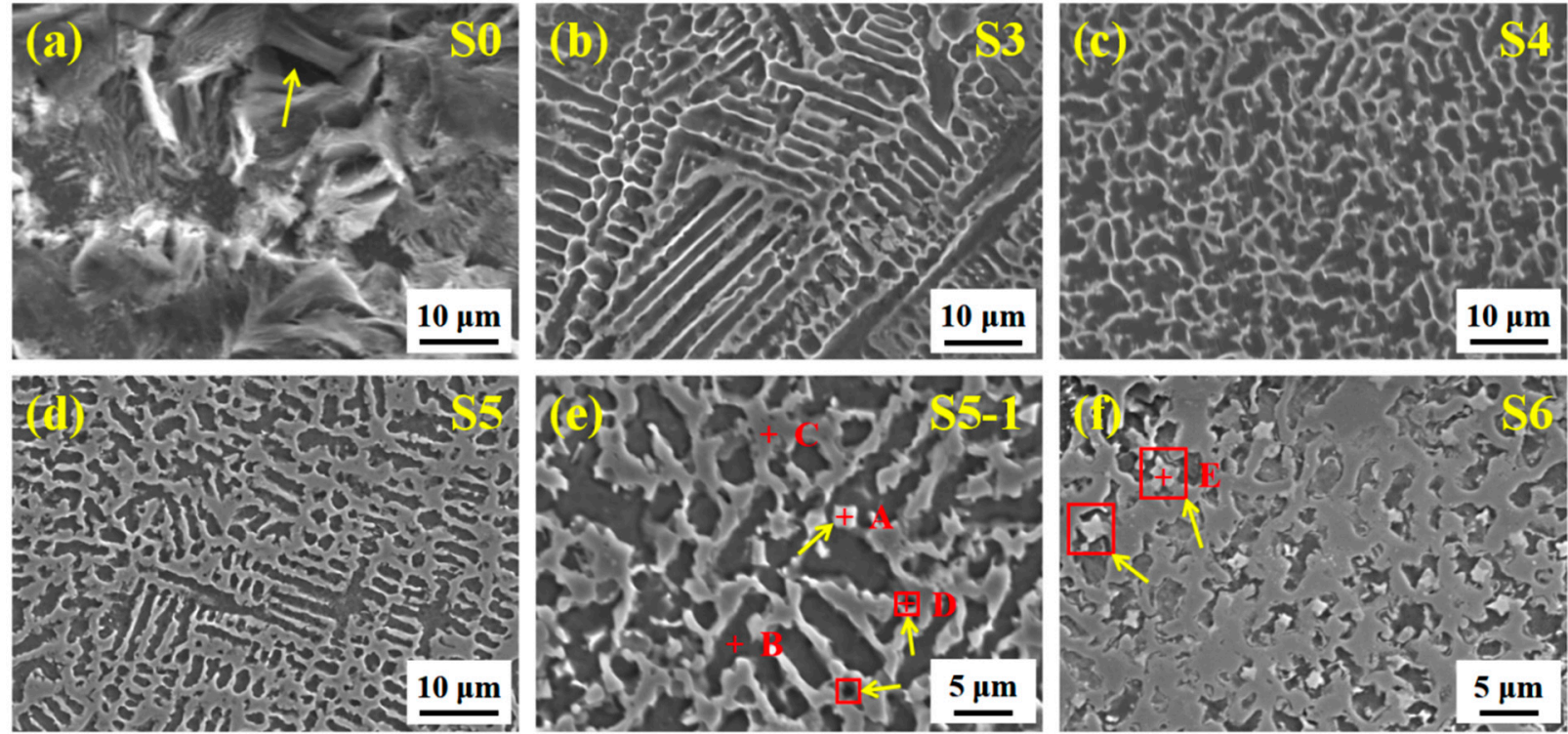

Figure 12. Corrosion surface morphology in Figure 11. (a) S0; (b) S3; (c) S4; (d) S5; (e) enlarged image of S5; (f) S6.
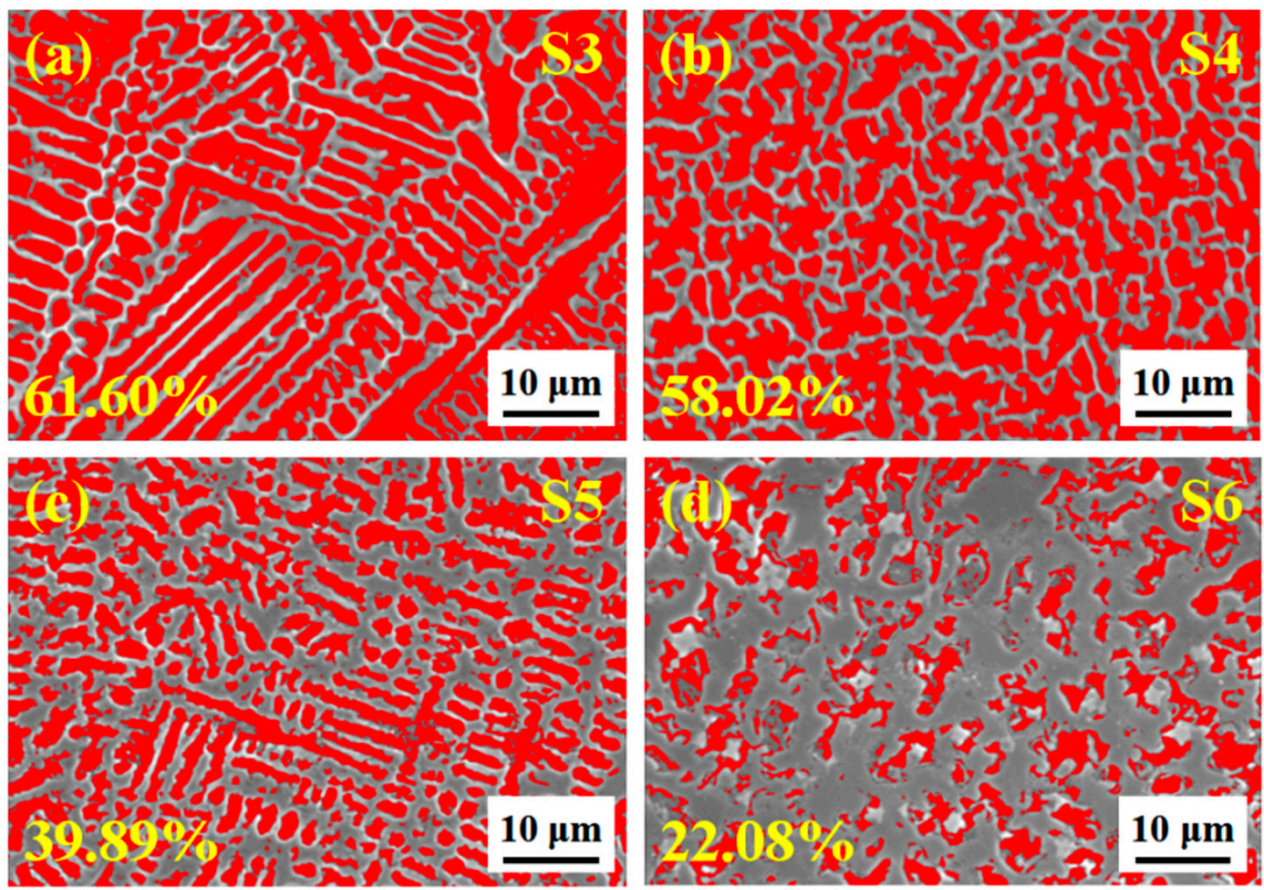

Figure 13. Quantitative analysis image and porosity of corrosion area in Figure 12. (a) S3; (b) S4; (c) S5; (d) S6.

Table 3. Elemental concentrations of the corrosion areas in Figure 12 (wt.\%).

\begin{tabular}{cccccccc}
\hline Area & $\mathbf{F e}$ & $\mathbf{N i}$ & $\mathbf{N b}$ & $\mathbf{T a}$ & $\mathbf{C}$ & $\mathbf{C r}$ & $\mathbf{O}$ \\
\hline $\mathrm{A}$ & 13.49 & 3.57 & 29.82 & 33.02 & 13.97 & 1.12 & 5.01 \\
$\mathrm{~B}$ & 60.01 & 21.34 & 0.09 & 0.09 & 12.63 & 1.00 & 4.26 \\
$\mathrm{C}$ & 72.26 & 17.15 & 1.46 & 0.54 & 5.82 & 1.64 & 1.13 \\
$\mathrm{D}$ & 71.42 & 24.05 & 0 & 0 & 2.11 & 1.31 & 1.01 \\
$\mathrm{E}$ & 6.42 & 1.68 & 38.6 & 39.38 & 11.58 & 2.34 & $/$ \\
\hline
\end{tabular}

Furthermore, a small number of corrosion pits in the dot-shape (point D) without $\mathrm{Nb}$-Ta elements are observed along the grain boundary, and the $\mathrm{C}$ content is also the 
lowest. Specifically, the corrosion pits are distributed along the grain boundaries without $(\mathrm{M}: \mathrm{Nb}, \mathrm{Ta}) \mathrm{C}$, which indirectly certificates the effect of $(\mathrm{M}: \mathrm{Nb}, \mathrm{Ta}) \mathrm{C}$ on the corrosion resistance of the composite coating. At point $\mathrm{E}$, a large petal shape $(\mathrm{M}: \mathrm{Nb}, \mathrm{Ta}) \mathrm{C}$ containing high $\mathrm{Nb}-\mathrm{Ta}$ restrains the grain corrosion and presents the shallowest grain corrosion pits. In addition, the $\mathrm{Nb}$-Ta element-formed oxides force the reduction and increase of the $\mathrm{Cr}$ dissolved in the electrolyte [22].

\section{Conclusions}

In this paper, the (M:Nb,Ta)C/Ni35 composite coating prepared by the in situ synthesis was discussed. The increase of ceramic micro-particles changed the morphology of ( $\mathrm{M}: \mathrm{Nb}, \mathrm{Ta}) \mathrm{C}$ constantly with the size from sub-micron to the micron. The $(\mathrm{M}: \mathrm{Nb}, \mathrm{Ta}) \mathrm{C}$ dispersed along the grain boundary inhibits the growth of grains. During friction, the spherical structure exhibited a rolling lubrication effect and the petal structure provided a stronger attachment ability to resist shear. The grain corrosion pits with a high content of ceramic particles are relatively shallow. Some corrosion pits in the dot-shape were distributed along the grain boundaries without $(\mathrm{M}: \mathrm{Nb}, \mathrm{Ta}) \mathrm{C}$.

Author Contributions: Conceptualization, G.J.; investigation, L.C. and X.C.; methodology, Y.W.; resources, L.C. and Y.W.; supervision, C.C.; funding acquisition, C.C.; writing-original draft, G.J.; writing-review and editing, Y.W. and X.C. All authors have read and agreed to the published version of the manuscript.

Funding: This research was funded by the National Natural Science Foundation of China (Nos. 51875267 and 51505198), National Key R\&D Program of China (2017YFB1103603), Colleges and Universities in Jiangsu Province "Qing Lan" Engineering Backbone Teachers Funded Project and Young Key Teachers Program of Jiangsu University.

Institutional Review Board Statement: We choose to exclude this statement.

Informed Consent Statement: We choose to exclude this statement.

Data Availability Statement: We choose to exclude this statement.

Acknowledgments: The authors greatly appreciate the financial support from the National Natural Science Foundation of China (Nos. 51875267 and 51505198), National Key R\&D Program of China (2017YFB1103603), Colleges and Universities in Jiangsu Province "Qing Lan" Engineering Backbone Teachers Funded Project and Young Key Teachers Program of Jiangsu University.

Conflicts of Interest: The authors declare that they have no known competing financial interest or personal relationships that could have appeared to influence the work reported in this paper.

\section{References}

1. Chen, X.Y.; Guo, L.T.; Liu, X.M.; Feng, W.; Li, B.E.; Tao, X.Y.; Qiang, Y.H. Effect of laser parameters on the microstructure of bonding porcelain layer fused on titanium. Opt. Mater. 2017, 71, 136-140. [CrossRef]

2. Pang, X.M.; Zhou, F.L.; Li, B.; Jiang, J.X.; Zhou, J.X. Optical thermostability and weatherability of TiN/TiC-Ni/Mo cermet-based spectral selective absorbing coating by laser cladding. Opt. Mater. 2021, 117, 111195. [CrossRef]

3. Zhang, C.S.; Shen, X.H.; Wang, J.T.; Xu, C.H.; He, J.Q.; Bai, X.L. Improving surface properties of Fe-based laser cladding coating deposited on a carbon steel by heat assisted ultrasonic burnishing. J. Mater. Res. Technol. 2021, 12, 100-116. [CrossRef]

4. Liu, C.; Wang, J.F.; Tian, L.H.; Liu, Z.G.; Wang, J.X.; Zhang, J.X. Properties and formation mechanism of cladding layer on highstrength low-alloy steel subjected to ultrasonic impact treatment with titanium alloy pin. Surf. Coat. Technol. 2021, 418, 127256. [CrossRef]

5. Liu, J.C.; Li, L.J. Effects of powder concentration distribution on fabrication of thin-wall parts in coaxial laser cladding. Opt. Laser Technol. 2005, 37, 287-292. [CrossRef]

6. Yamaguchi, T.; Hagino, H. Effects of the ambient oxygen concentration on WC-12Co cermet coatings fabricated by laser cladding. Opt. Laser Technol. 2021, 139, 106922. [CrossRef]

7. Jiang, J.X.; Pang, X.M.; Zhou, J.X.; Li, B.; Zhou, F.L. Optical performance and corrosion resistance of TiN/Ni multiphase cermet by laser cladding. Opt. Laser Technol. 2021, 143, 107308. [CrossRef]

8. Zhang, H.; Zou, Y.; Zou, Z.D.; Shi, C.W. Effects of chromium addition on microstructure and properties of TiC-VC reinforced Fe-based laser cladding coatings. J. Alloys Compd. 2014, 614, 107-112. [CrossRef] 
9. Nam, S.; Kim, C.; Kim, Y.M. Microstructure evolution of in-situ (Ti,W)C- $\mathrm{Al}_{2} \mathrm{O}_{3}$ particle-reinforced alloy fabricated by gas tungsten arc cladding. Surf. Coat. Technol. 2018, 354, 1-9. [CrossRef]

10. Wang, X.H.; Zou, Z.D.; Qu, S.Y. Microstructure of Fe-Based Alloy Hardfacing Coating Reinforced by TiC-VC Particles. J. Iron Steel Res. Int. 2006, 13, 51-55. [CrossRef]

11. Gu, Y.F.; Liu, J.X.; Wang, Y.; Xue, J.X.; Wang, X.G.; Zhang, H.B.; Xu, F.F.; Zhang, G.J. Corrosion behavior of TiC-SiC composite ceramics in molten FLiNaK salt. J. Eur. Ceram. Soc. 2017, 37, 2575-2582. [CrossRef]

12. Jiang, G.Q.; Cui, C.Y.; Chen, L.; Zhao, K.; Cui, X.G. Effects of powder size and preset thickness on microstructure and properties of Ni35 thin coating prepared by laser cladding. Appl. Opt. 2021, 60, 9535-9542. [CrossRef]

13. Suryanarayana, C.; Norton, M.G. X-ray Diffraction: A Practical Approach; Springer: Berlin/Heidelberg, Germany, 2013.

14. Zhang, M.Y.; Li, M.; Wang, S.F.; Chi, J.; Ren, L.S.; Fang, M.; Zhou, C. Enhanced wear resistance and new insight into microstructure evolution of in-situ (Ti,Nb)C reinforced 316 L stainless steel matrix prepared via laser cladding. Opt. Lasers Eng. 2020, 128, 106043. [CrossRef]

15. Jiao, X.Y.; Wang, C.M.; Gong, Z.Q.; Wang, G.M.; Sun, H.F.; Yang, H.R. Effect of Ti on T15M composite coating fabricated by laser cladding technology. Surf. Coat. Technol. 2017, 325, 643-649. [CrossRef]

16. Dong, G.; Yan, B.; Deng, Q.L.; Yu, T. Effect of niobium on the microstructure and wear resistance of nickel-based alloy coating by laser cladding. Rare Met. Mater. Eng. 2011, 40, 973-977.

17. Fu, W.; Yong, Y.W.; Deng, Q.L.; Dong, G. Effect of in-situ precipitation of NbC by laser cladding on microstructure and properties of Ni25 cladding layer. In Proceedings of the 2015 Academic Annual Conference of Shanghai Laser Society, Shanghai, China, 16 December 2015. (In Chinese)

18. Hu, G.X.; Cai, X.; Rong, Y.H. Fundamentals of Materials Science; Shanghai Jiaotong University Press: Shanghai, China, 2010. (In Chinese)

19. Li, Q.; Zhang, D.W.; Lei, T.Q.; Chen, C.Z.; Chen, W.Z. Comparison of laser-clad and furnace-melted Ni-based alloy microstructures. Surf. Coat. Technol. 2001, 137, 122-135. [CrossRef]

20. Zhang, D.W.; Lei, T.C.; Zhang, J.G.; Ouyang, J.H. The effects of heat treatment on microstructure and erosion properties of laser surface-clad Ni-base alloy. Surf. Coat. Technol. 1999, 115, 176-183. [CrossRef]

21. Cao, Y.B.; Zhi, S.X.; Gao, Q.; Tian, X.T.; Geng, T.; Guan, X.; Qin, C. Formation behavior of in-situ NbC in Fe-based laser cladding coatings. Mater. Charact. 2016, 119, 159-165. [CrossRef]

22. Li, Z.Y.; Yan, H.; Zhang, P.L.; Guo, J.L.; Yu, Z.S.; Ringsberg, J.W. Improving surface resistance to wear and corrosion of nickelaluminum bronze by laser-clad TaC/Co-based alloy composite coatings. Surf. Coat. Technol. 2021, 405, 126592. [CrossRef] 